$\begin{array}{ll}\begin{array}{l}\text { Peseta problems } \\ \text { Spain seeks private } \\ \text { funds for new } \\ \text { research centres } \\ \text { p550 }\end{array} & \begin{array}{l}\text { New telescope will } \\ \text { aid search for alien } \\ \text { intelligence } \\ \text { p551 }\end{array}\end{array}$

\title{
United States backs soil strategy in fight against global warming
}

\section{Paul Smaglik, Washington}

The US government is seeking to take advantage of farming practices to help reduce overall greenhouse-gas emissions. Building on the idea that increased carbon sequestration by crops and trees could reduce the need to cut emissions, the US State Department last week suggested amending the Kyoto Protocol on climate change to take greater account of forestry and farmland management.

Signatories to the Kyoto Protocol have agreed to reduce greenhouse-gas emissions during $2008-2012$ by 5\% from their 1990 levels. Although it has been signed by over 80 countries, the protocol has yet to come into force - it can only be implemented once 55 signatories have ratified the agreement; so far just over 20 countries have taken this step.

In assessing emissions, the protocol makes provisions for greenhouse gases sequestered in forests. The US State Department wants to broaden the category of acknowledged carbon 'sinks' - the soil, plants and trees that mop up carbon from the atmosphere - to include land used for crops and grazing.

The impact of the new definition would depend on how the land is managed. For example, conventionally farmed land would

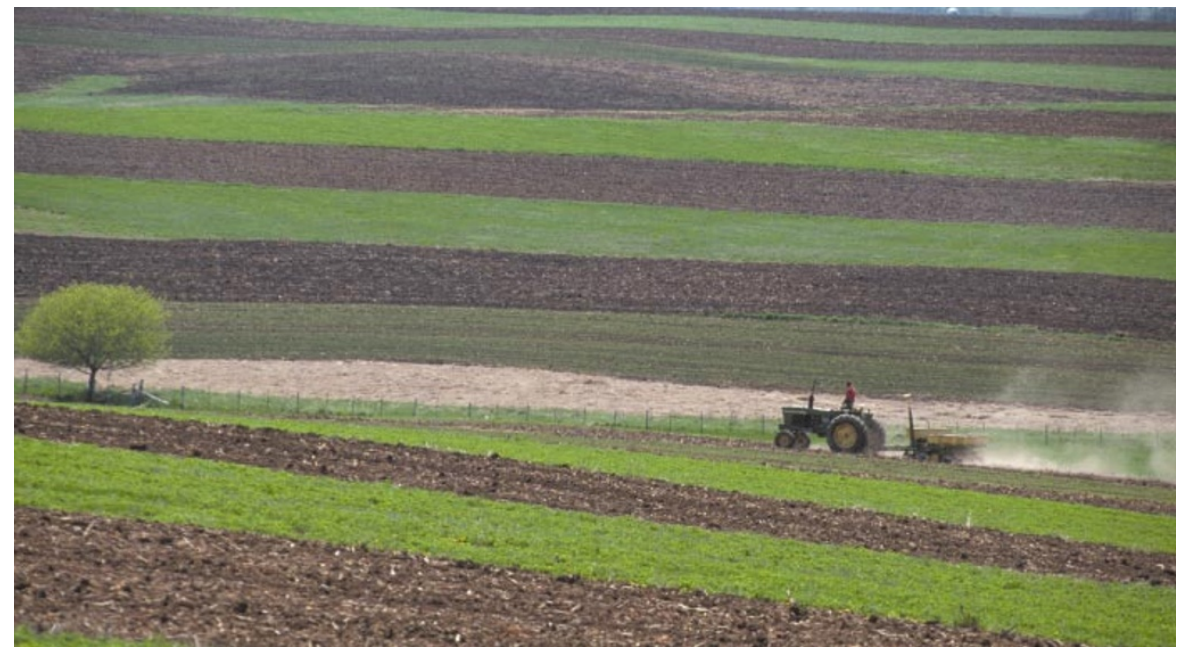

Going green: careful land management could help the United States meet Kyoto emissions targets.

count as a debit because ploughing soil releases carbon into the atmosphere. But fields worked using 'no-till' techniques would count as a credit, as they keep the carbon trapped in the soil.

This broader definition would offer US industry potential benefits. Nearly half of the country's annual obligation under the Kyoto

\section{Royalty-free rice arrives on the web}

\section{David Dickson}

Keen to polish its global image, the multinational life sciences company Monsanto has announced royalty-free licences to its technology for producing rice varieties with enhanced levels of provitamin A.

The move comes four months after the company revealed that it had completed the draft sequencing of the rice genome, and had agreed to make the results available to researchers (see Nature 404, 534; 2000). Last week's announcement included news of Monsanto's new website giving researchers access to its genome sequence database.

In a statement, Monsanto said that both moves were part of its ongoing commitment to global agricultural research aimed at facilitating the use of the company's technologies and data for the common good. The draft sequence data have already been transferred to Japan's Ministry of Agriculture, Forestry and Fisheries as the lead agency of the International Rice Genome Sequencing Project.

The latest moves by Monsanto, which have received a cautious welcome from environmentalist groups, follow a report issued last month by seven national scientific academies urging companies to offer certain proprietary technologies free to the developing world (see Nature 406, $115 ; 2000)$.

| http://www.rice-research.org
Protocol could be met by sinks, so emissions from cars, factories and power plants would not need to be reduced as drastically as they would under the current definition.

The revised definition might also make the protocol more palatable to US senators, who so far have been hesitant about ratifying the agreement. Giving tax credits to companies that plant trees, or crop subsidies to farmers who use no-till methods, could be less costly than forcing electric companies to switch to cleaner plants or convincing consumers to drive cars that are more fuel efficient.

But the broader definition may face objections from countries that have less forestry and farmland than the United States. And although scientists generally agree that soil, plants and trees trap carbon, there is considerable uncertainty over how to measure the specific dynamics of the process.

Some scientists warn that forests and fields could become saturated with carbon, so their impact as a sink might be overestimated. They also worry about the lack of permanence to this approach - unexpected forest fires can release carbon back into the atmosphere, as can turning over soil in a field that for years was planted using no-till methods.

Under the US proposal, sinks could remove as much as 300 million tonnes of carbon a year in the United States through 
revised land management. But for 2008-2012 the official figure may be smaller, partly because of concerns over how sinks should be measured, says Frank Loy, Undersecretary of State for Global Affairs. Counting only some of the carbon trapped in sinks would also help to pacify countries with fewer forests and fields than the United States, he adds.

Loy argues that using the broad definition of sinks to meet the Kyoto targets is not cheating, as scientists agree that sinks play a role in reducing greenhouse-gas levels in the atmosphere. But how large this role is, and how it should be quantified, is another issue. This summer, the Intergovernmental Panel on Climate Change produced a report detailing the problems of measuring how much carbon is trapped and released in land-use strategies.

Loy thinks such difficulties can be overcome - sinks are "quite measurable", he says. But Eileen Claussen, president of the Pew Center on Global Climate Change, disagrees. She emphasizes the forest fire problem and points out that soil may become carbon-saturated sooner than expected. "Could these things be loopholes? Yes," she says.

Claussen believes that sinks should be counted to some extent, but questions the level to which the US proposal relies on them. "I don't think the US plan as conceived is what's going to be accepted internationally," she says.

William Moomaw, professor of international environmental policy at Tufts University in Massachusetts, calls the proposed system a huge accounting problem. $\mathrm{He}$ is concerned that it gives credits for reforestation, but misses instances of deforestation. "You can't just count the sinks and not count the sources," he says.

Moomaw also wonders whether countries will get credits for planting trees before 2008. Credit for planting should only count after it offsets emissions, as well as deforestation and development, he says. He also notes that different kinds of trees and soils have different capacities for holding carbon. Because of this complexity, Moomaw says the Kyoto Protocol should only count obvious, easily measurable debits and credits.

Moomaw is also concerned about the way the United States has emphasized buying other countries' emission credits, supporting emission reductions projects in developing countries, and relying on sinks, rather than adopting tough domestic measures to reduce carbon emissions. "We're looking for every possible way to show we are making a reduction without asking anyone [in the United States] to do anything," he says.

http://www.state.gov/www/global/global_issues/ climate/fs-000801_unfccc1_subm.html

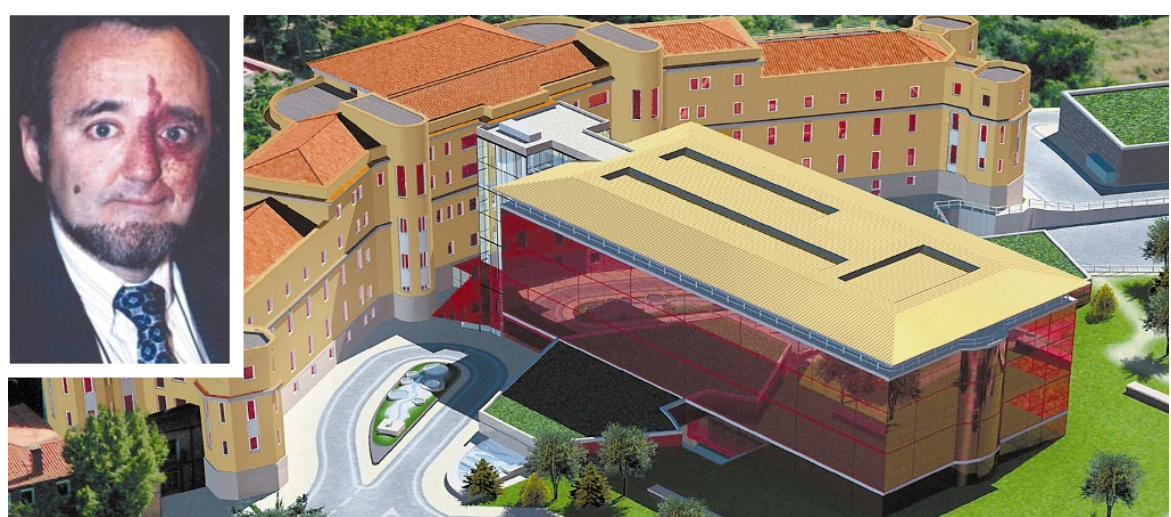

Shaky foundations? Barbacid (inset) warns against relying on industry money to build cancer centre.

\section{Spanish biomedical centres face funding uncertainty}

\section{Xavier Bosch, Barcelona}

When the Spanish government announced plans in September 1997 to open two worldclass research centres in cancer and cardiovascular disease, the move was widely welcomed. But there were immediately questions over their long-term support.

Now, it seems, the government is hoping that the two Madrid-based centres - the National Centre of Cancer Research (CNIO), due to open next spring, and the Institute of Cardiovascular Diseases (IICV), work on which will probably start in 2001 - will receive a hefty chunk of their funding from private industry.

The government had pledged to meet the financial needs of both, including their construction and equipment. But the new minister of health, Celia Villalobos, appointed in April after a general election, appears to be retreating from this commitment.

The ministry has now announced that it will raise Ptas5.5 billion (US $\$ 31$ million) this year from an agreement with Farmaindustria, a group of 240 drug companies. But this leaves the centres' long-term prospects in doubt.

Mariano Barbacid, head of CNIO and internationally known for his role in the discovery of human oncogenes, fears that the ministry may no longer fulfil its commitments - including providing Ptas 3.2 billion to CNIO's budget next year.

Barbacid says that he hopes this promise will not be dropped during the autumn's budget discussions. "The collaboration with Farmaindustria should come through research projects," he says. "Pharmaceutical companies should not finance infrastructure [of the $\mathrm{CNIO}]$, as this agreement is only for this year, and the future would be left uncertain.'

Farmaindustria spokesman Carlos Nicolás confirms that industry support is just for one year. "Nobody knows what will happen next year." Others claim that the agreement is part of a longer-term deal between the government

^ 2000 Macmillan Magazines Ltd and the pharmaceutical industry.

They point to a recent statement by finance minister Rodrigo Rato who announced the government's intention to "promote a pact with the pharmaceutical industry to avoid spending on drugs increasing at more than $8 \%$ a year".

Some believe that Villalobos wanted a quick fix to the research centres' money problems because she is more concerned about the broad funding of healthcare than research.

Although the IICV is not likely to open until 2002, it is due to receive Ptas1.7 billion this year to start construction work. Salvador Moncada, director of the Wolfson Institute for Biomedical Research at University College, London, who is said by some to have been asked to head the centre, is among those urging the Spanish government to make a long-term investment in research.

"A commitment to research does not just mean obtaining a one-off donation from the drug industry, but the stable and long-term financing needed to allow the development of a solid scientific base," says Moncada, an adviser on the creation of the centre.

By law, 1\% of Spain's health budget must be devoted to research. To reach this target, Moncada is proposing that the ministry guarantees providing at least $0.25 \%$, with the rest coming from the drug and food industries.

Given the Mediterranean diet's role in protecting against heart disease, "authorities should regard the food industry as a potentially important source of biomedical research support," says Moncada.

Villalobos appears to share Moncada's belief that industry should fund basic biomedical research. Shortly before the agreement with Farmaindustria was announced, she said that she was seeking "a stable, longterm solution to finance both the CNIO and the IICV that may eventually rely on a serious deal with the industry".

inttp://www.cnio.es 